\title{
STUDY ON LASER-ASSISTED SPINNING OF AGED ALUMINUM ALLOY SHEET
}

\author{
Fengqi WANG, Jinyu RAN, Chenyang DU, Ruocun SONG, Zhongqi YU \\ Shanghai Key Laboratory of Digital Manufacture for Thin-walled Structures, Shanghai Jiao Tong University, \\ Shanghai, China yuzha@situ.edu.cn,wangfengqi@situ.edu.cn
}

https://doi.org/10.37904/metal.2021.4109

\begin{abstract}
To explore the feasibility of directly spinning thin-walled components from aged aluminum alloy sheets under rapid laser heating, the laser-assisted spinning process of aged 7075-T6 aluminum alloy was carried out by means of an ellipsoid component shear spinning test. Compared with cold spinning, the critical thinning of the laser-assisted spun component was more than $30 \%$ higher than that of the cold spun component, and the laser-assisted spun component has good geometric accuracy, which indicates that the formability of the 7075T6 aluminum alloy can significantly be improved with the laser-assisted spinning process. Moreover, the Vickers hardness tests for the spun components were arranged to evaluate its mechanical properties. The measurement results show that the micro hardness of the laser-assisted spun component is significantly decreased. The reason for the decrease phenomenon is that the GP zone of the 7075-T6 re-dissolves and the fine precipitates grow up to coarse precipitates.
\end{abstract}

Keywords: Laser-assisted spinning, aged aluminum alloy, spinning ability, hardness, precipitate

\section{INTRODUCTION}

High strength aluminum alloy, Al-Cu-Mg and Al-Zn-Mg-Cu series aluminum alloy, is widely used in aerospace and national defense fields due to its high specific strength and toughness [1,2]. Generally, the stiffness of large thin-walled components is very weak, and the quenching process brings significant thermal deformation, which makes it difficult to ensure the geometric accuracy of the components. Therefore, a rapid heating stamping technology with the natural aged aluminum blank is developed in recent years, in which the pressed components with high geometric accuracy and mechanical property are obtained due to the omitted quenching procedure, meanwhile, the technological process is shorten [3].

At present, metal spinning is widely developed in aerospace aluminum alloy components. For hot spinning of metal with poor plasticity, a heating source with high efficiency and good controllability is a key precondition. Contrasted with induction heating and resistance heating, laser-assisted heating is an advanced technology due to its rapid and local heating. The heating area and temperature can be adjusted by the laser parameters and position during forming. In recent years, laser-assisted spinning technology has attracted the attention of numerous researchers. Klock [4] developed laser-assisted spinning technology for stainless steel and titanium alloy forming and found that the spinning ability of these materials was significantly improved and the intermediate annealing procedures were omitted. Romero [5] improved the poor formability of DP800 steel with laser-assisted spinning. Hino [6] revealed that the forming limit of AZ31 magnesium alloy increases with the laser power increases in laser-assisted incremental forming. Brummer [7] carried out the laser-assisted spinning of titanium alloy, and results show that the laser-assisted spinning could avoid cracking, improve geometric accuracy. Up to now, most of the researches focus on the improvement of forming limit of annealed material and geometric accuracy of thin-walled components by laser-assisted spinning. However, the research on the aged aluminum alloy of laser-assisted spinning and the micro mechanism are rarely published. 
In this paper, the laser-assisted shear spinning is used to study the formability, the geometric accuracy and mechanical property (micro hardness) of the AA7075-T6 thin-walled spun component, and the evolution of precipitates of the aged aluminum alloy introduced with the laser temperature field is investigated.

\section{EXPERIMENTAL}

In this study, the machine ZENN-100 CNC and YLR-1500 single-mode resonant laser transmitters were used for the laser-assisted spinning experiment. The laser incidence angle and irradiation distance were adjusted before spinning to ensure that the laser irradiation point is always concentrated on the blank zone in front of the roller. The blank can be heating rapidly and locally before forming. The laser-assisted spinning test setup is shown as Figure 1, which is composed of the mandrel 1, roller 2, tailstock 3, and laser maser 4.

A single-pass shear spinning test was carried out on an ellipsoidal mandrel. The dimension of the mandrel is shown in Figure 2, and the red line represents the trajectory of the roller. The initial blank is the 7075-T6 aluminum alloy sheet with $1.85 \mathrm{~mm}$ thickness. the cold spinning and laser-assisted spinning tests were arranged in this study. The parameters for the above tests are: the laser power $1200 \mathrm{~W}$, the irradiation distance $200 \mathrm{~mm}$, constant linear velocity $100 \mathrm{~mm} / \mathrm{s}$. Graphite powder was coated on the surface of the initial sheet before spinning to increase the laser absorptivity and decrease the friction.
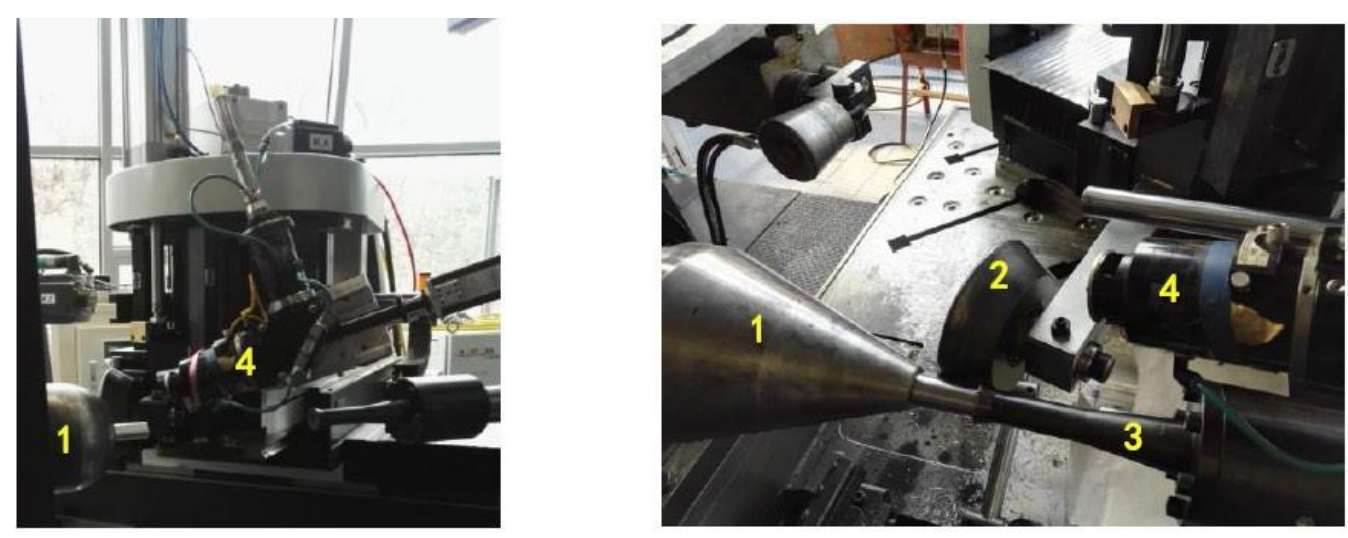

1-Mandrel(left: ellipsoid, right: cone), 2-Roller, 3-Tailstock, 4-Laser maser

Figure 1 Laser-assisted spinning test setup

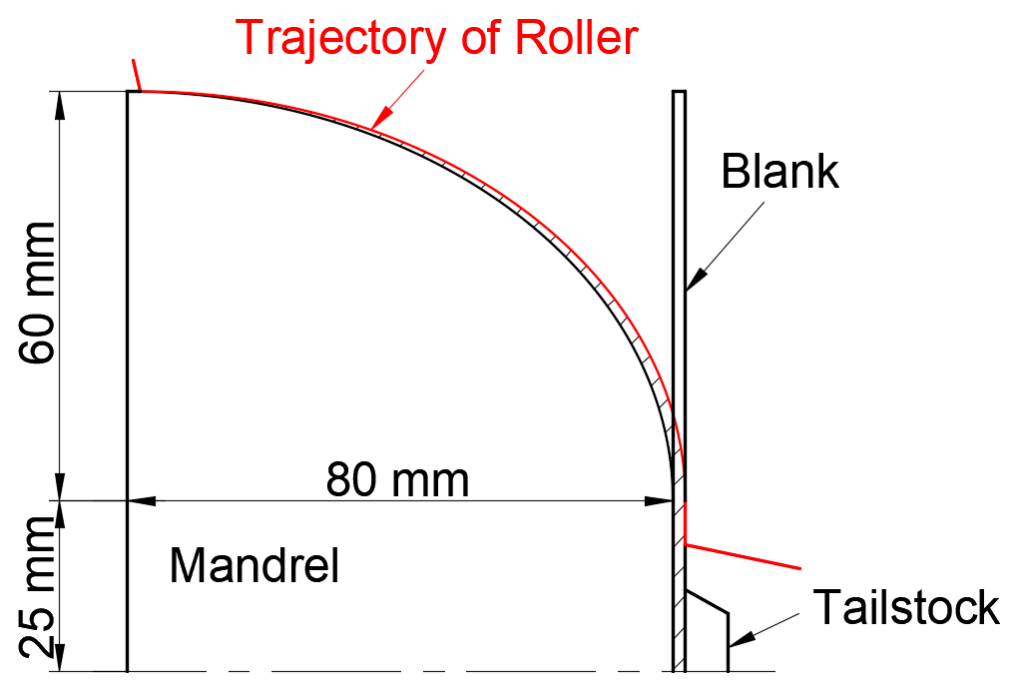

Figure 2 Dimension of the mandrel and trajectory of the roller 


\section{RESULTS AND DISCUSSIONS}

\subsection{Spinning ability}

The AA7075-T6 cold spun (CS) and laser-assisted spun (LAS) components are shown in Figure 3, respectively. It is obvious that the shear spinning ability of AA7075-T6 is very poor at room temperature, and a crack appears early on the CS component, as shown in Figure 3(a). However, the shear spinning ability of AA7075-T6 is improved significantly under the LAS, a deeper spun component was obtained, as shown in Figure 3(b). Figure 4 shows the gap of the part-mould of the spun components at the final moment. The partmould gap of CS component is larger because of the higher yield stress of AA7075-T6 at room temperature, as shown in Figure 4(a). For the LAS, the part-mould gap is very small, as shown in Figure 4(b).
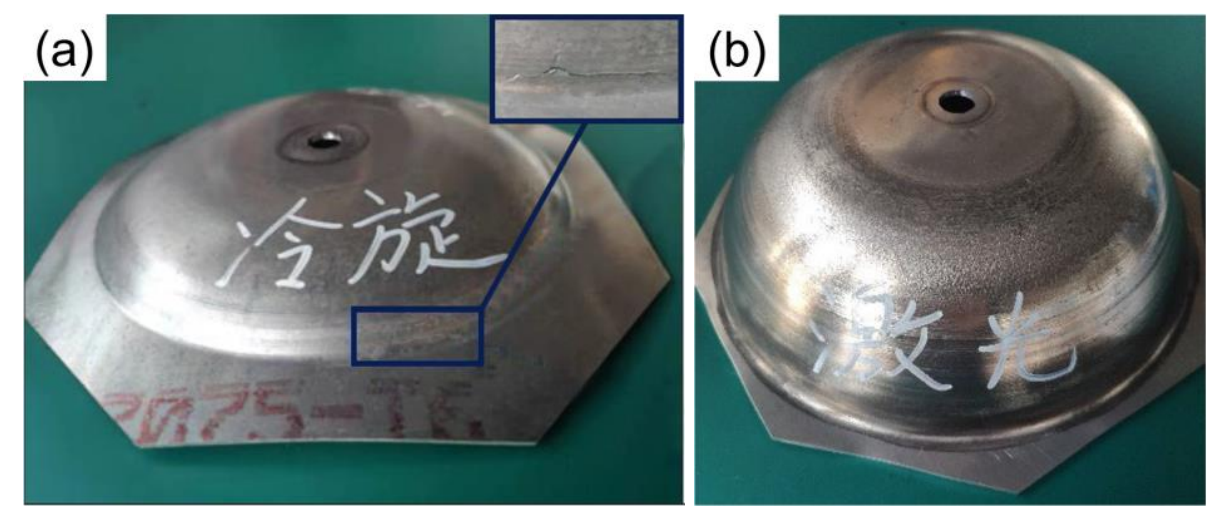

Figure 3 Photo of 7075-T6 spun componets: (a) CS, (b) CS
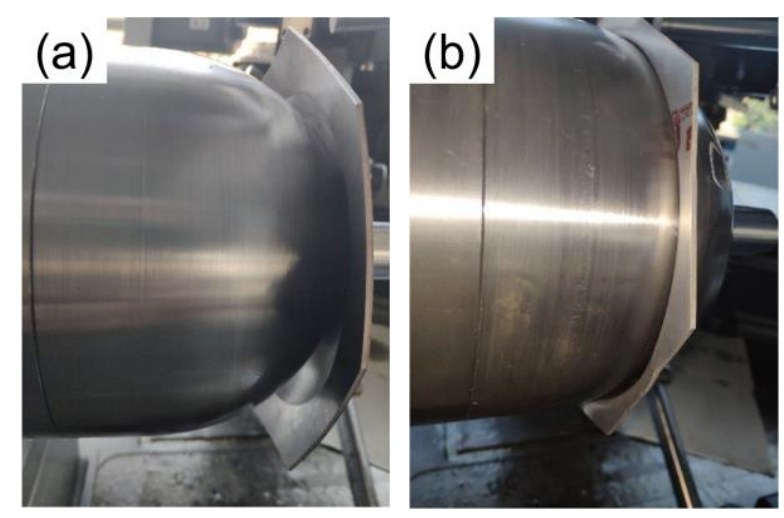

Figure 4 Contour of 7075-T6 spun componets in the mandrel: (a) CS, (b) CS

FARO measurement arm was used to scan the spun components and then the geometries were reconstructed. The thickness of CS componet near the crack is $1.19 \mathrm{~mm}$, and the minimum thickness of LAS componet is $0.62 \mathrm{~mm}$. That is, the thinning of CS and LAS componets are $35.8 \%$ and $66.7 \%$, respectively. In addition, there is no crack on LAS component, which indicates that the thinning can reach a higher value further. Therefore, it is obvious that the spinning ability of AA7075-T6 is increased significantly, at least $30.9 \%$, under the laserassisted forming conditions in this study.

\subsection{Micro hardness}

The square samples with the size of $1 \mathrm{~mm} \times 1 \mathrm{~mm}$ were cut from the CS and LAS components along the generatrix direction, all of the intervals between the samples maintain $1 \mathrm{~mm}$. Therefore, five samples were taken from the CS component mark as Sample 1 to 5 , and eight samples were taken from the LAS component mark as Sample 1 to 8, as shown in Figure 5. 


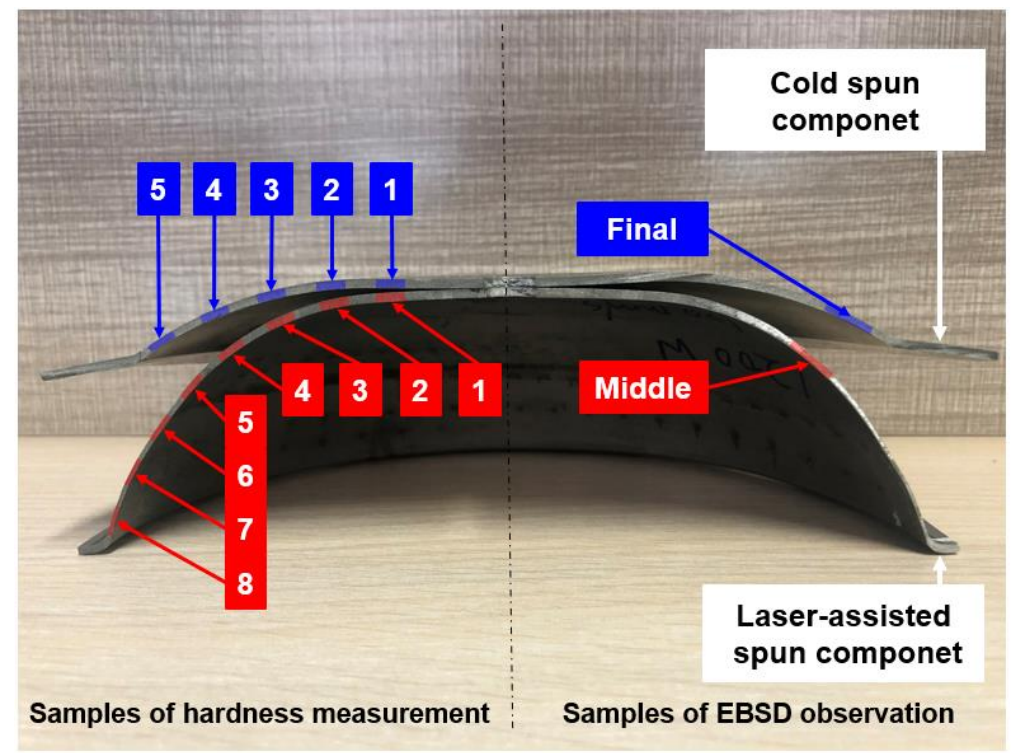

Figure 5 Positions of micro hardness measurement and microstructure observation

The Vickers hardness tests were carried out to evaluate the mechanical property of the inner surface (IS) and outer surface (OS) of the samples at a load of $200 \mathrm{~g}$ in a HXD-1000TMJC/LCD, and the average value is calculated after measuring three times each sample. Micro hardness of spun components from the forming beginning to the ending is shown in Figure 6. For the CS component, the micro hardness of the OS is slightly higher than that of the IS. The reason is that the roller contacts on the OS of the sheet directly, the strain gradient exists along the thickness direction in the deformed material, which leads to a higher hardening effect for the OS. It should be noted that the hardness values for the IS and OS are approximate. For the LAS component, the hardness magnitudes show a decreasing tendency both of the OS and IS, and it is lower than the hardness of the initial sheet, HV186.2. The minimum hardness of LAS is HV99.7, which is $53.5 \%$ of the initial sheet approximately. In general, annealed 7075 aluminum alloy is about HV60. To a certain extent, the strength index of 7075-T6 aluminum alloy can be retained after LAS. Obviously, the micro hardness on the LAS component is quite different from that of the CS component. The effect of the laser temperature field during spinning on the microstructure evolution of the material is further explored by means of microstructure observation in the next section.
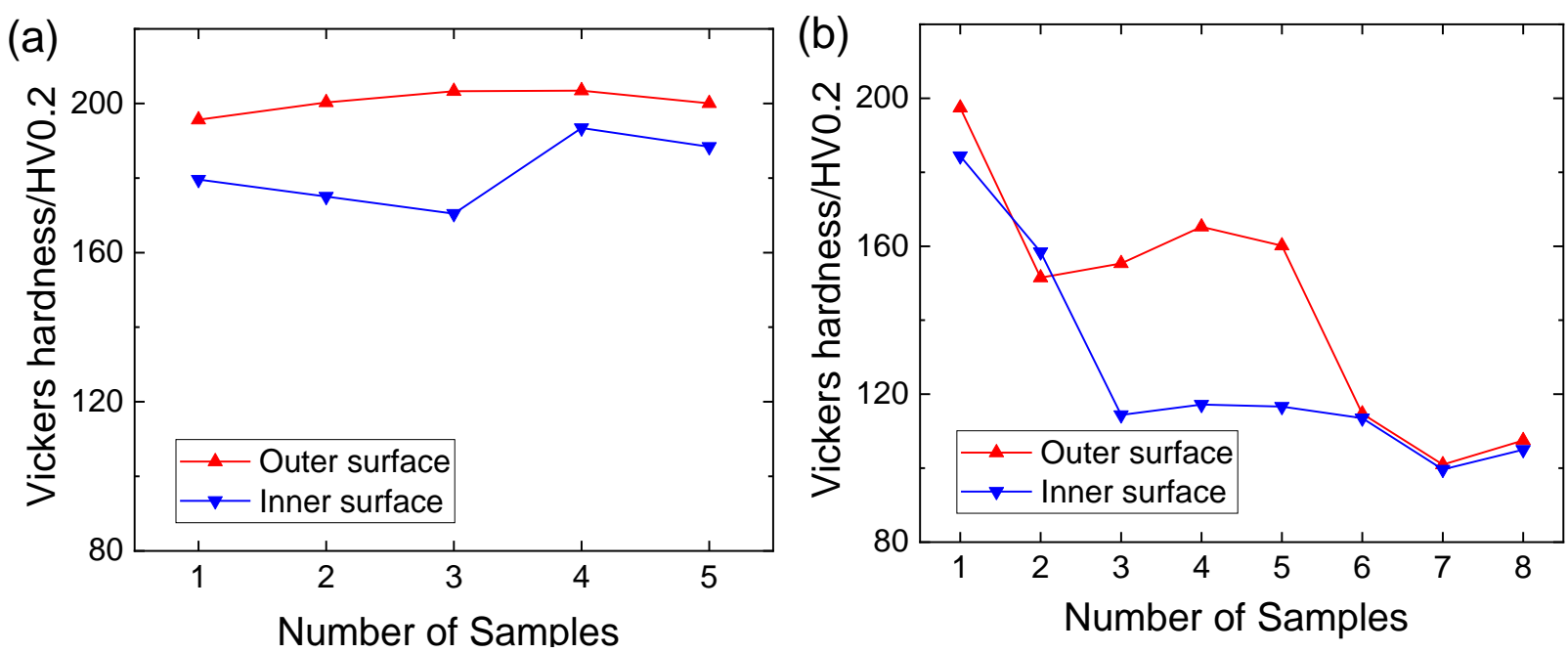

Figure 6 Micro hardness of AA7075-T6 components: (a) CS, (b) LAS 


\subsection{Microstructure observation}

The positions of samples for microstructure observation are shown in Figure 5. A sample was cut at the ending point of the CS component, where the deformation is most severe. In order to ensure the microstructure observations possessed comparability, another sample, which has the same thinning as the sample in the CS component, was cut at the middle position on the LAS component. It is worth noticing that the sample position for the LAS component shows a significant hardness difference between the IS and OS. The TEM samples were punched, ground and twin jet electropolished in a mixed solution of $\mathrm{HNO}_{3}$ and methanol (1:4 in volume) at $-30^{\circ} \mathrm{C}$. The morphologies and distributions of the second phases are analyzed by the TALOS F200X G2 transmission electron microscope.

AA7075 is an Al-Zn-Mg-Cu series alloy. The main strengthening alloy elements are $\mathrm{Zn}$ and $\mathrm{Mg}$. The precipitation sequence of the alloy during aging treatment is: supersaturated solid solution (SSS) $\rightarrow$ solutevacancy $\rightarrow$ GP zone $\rightarrow$ intermediate phase $\eta^{\prime}$ or $T^{\prime} \rightarrow$ equilibrium phase $\eta\left(M Z n_{2}\right)$ or $T\left(M_{32}(A l, Z n)_{49}\right)[8,9]$. $\eta^{\prime}$ is semi-coherent with the Al matrix, which is the main strengthening phase, and $\eta$ is non-coherent with the $\mathrm{Al}$ matrix, which results in a significant reduction in its strengthening effect[10]. Besides of the precipitate phases, the precipitation free zones (PFZs) by interacting with vacancies in the Al matrix grain boundary is an important factor affecting the mechanical properties. The material strength and ductility are decreased with the width of PFZs increase [11,12].

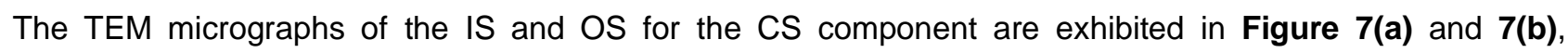
respectively. It can be observed that fine phases with different morphologies are evenly distributed within the grains. The fine plate-like and polyhedral precipitates are GP zone, spherical precipitates are T', whereas short rod-like precipitates are n'. Meanwhile, PFZs can be observed distinctly in the grain boundary. The width of the PFZs of the IS is $42.3 \mathrm{~nm}$, which is a little wider than $36.9 \mathrm{~nm}$ at the OS. The observation explains that the micro hardness of IS is slightly lower than the OS of the CS component. Figure 7(c) and 7(d) show the TEM micrographs of the IS and OS for the LAS component, respectively. Apparently, the sizes of the precipitated phases are significantly larger than that of the CS component. The grown granular $T$ and the short rod-shaped $\eta$ can clearly be observed, and the small GP zone re-dissolved. The sizes of the dispersed precipitates of the OS are slightly smaller than that of the IS. The width of the PFZs at the OS is $111.3 \mathrm{~nm}$, but the width of the PFZs of the IS is about $160.7 \mathrm{~nm}$. It means that the strength of grain boundaries of the IS is weaker than the OS, which is the reason of the micro hardness of the IS is much smaller.
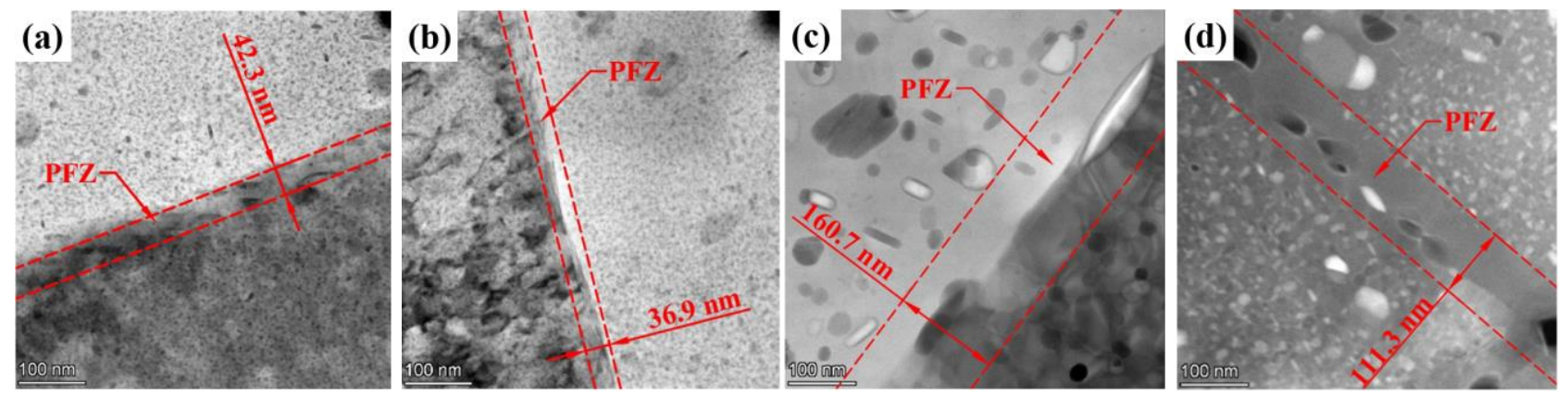

Figure 7 TEM micrographs of AA7075 parts: (a) IS of CS, (b) OS of CS, (c) IS of LAS, (d) OS of LAS

\section{CONCLUSIONS}

In this paper, the laser-assisted spinning process of 7075-T6 aluminum alloy was investigated. The conclusions are summarized as follows: 
The spinning ability of the 7075-T6 aluminum alloy can significantly be improved under laser-assisted spinning process. Compared with cold spinning, the laser-assisted spinning can achieve higher thinning, and also acquire better geometric accuracy.

The micro hardness of the spun component showed a decreasing tendency in the laser-assisted forming. Under the forming conditions in this study, the minimum hardness is $53.5 \%$ of the initial sheet $7075-\mathrm{T} 6$ approximately.

For the LAS component, the GP zone re-dissolved, fine precipitates $\left(T^{\prime}, \eta^{\prime}\right)$ grew up and the PFZs widen were the reason for the decrease of micro hardnesses compared with the initial 7075-T6 sheet.

\section{ACKNOWLEDGEMENTS}

\section{The authors gratefully acknowledge the support of the National Natural Science Foundation of China}

(No. 51790175, No. 51675333 ).

\section{REFERENCES}

[1] TERESA, B., KONRAD, L., HENRYK, D. The influence of deformation method on 7075 aluminum alloys deformability parameters. In: METAL 2017: 26th Int. Conf. on Metallurgy and Materials. Brno, Czech Republic, 2017, pp. 1644-1651.

[2] KODETOVÁ, V., VLACH, M., LEIBNER, M., KUDRNOVÁ, H., HARCUBA, P., BAJTOŠOVÁ, L., CIESLAR, M. Thermal characteristics and electrical properties of hot deformed AA7075 alloys with and without Sc, Zr additions. In: METAL 2020: 29th Int. Conf. on Metallurgy and Materials. Brno, Czech Republic, 2020, pp. 1024-1029.

[3] MAENO, T., MORI, K., YACHI, R. Hot stamping of high-strength aluminum alloy aircraft parts using quick heating. CIRP Annals. 2017, vol. 66, issue 1, pp. 269-272.

[4] KLOCKE, F., WEHRMEISTER, T. Laser-Assisted Metal Spinning of Advanced Materials. In: Lasers in Manufacturing 2003: Proceedings of the 2nd International WLT-Conference Lasers in Manufacturing. Erlangen, Germany, 2003, pp. 195-200.

[5] ROMERO, P., OTERO, N., CABRERA, J. M., MASAGUÉ, D. Laser assisted conical spin forming of dual phase automotive steel. Experimental demonstration of work hardening reduction and forming limit extension. Physics Procedia. 2010, vol. 5, pp. 215-225.

[6] HINO, R., KAWABATA, K., YOSHIDA, F. Incremental Forming with Local Heating by Laser Irradiation for Magnesium Alloy Sheet. Procedia Engineering. 2014, vol. 81, pp. 2330-2335.

[7] BRUMMER, C., ECK, S., MARSONER, S., ARNTZ, K., KLOCKE, F. Laser-assisted metal spinning for an efficient and flexible processing of challenging materials. IOP Conference Series: Materials Science and Engineering. 2016, vol. 119, 012022.

[8] ZHAN, M., WANG, X., LONG, H. Mechanism of grain refinement of aluminium alloy in shear spinning under different deviation ratios. Materials \& Design. 2016, vol. 108, pp. 207-216.

[9] AFIFY, N., GABER, A., ABBADY, G. Fine Scale Precipitates in Al-Mg-Zn Alloys after Various Aging Temperatures. Materials Sciences and Applications. 2011, vol. 02, issue 5, pp. 427-434.

[10] RICHARD, D., ADLER, P. N. Calorimetric studies of 7000 series aluminum alloys: I. Matrix precipitate characterization of 7075. Metallurgical Transactions A. 1977, vol. 8, issue.7, pp. 1177-1183.

[11] WANG, Y., WU, X., CAO, L., TONG, X., ZOU, Y., ZHU, Q., TANG, S., SONG, H., Guo, M. Effect of Ag on aging precipitation behavior and mechanical properties of aluminum alloy 7075. Materials Science and Engineering: $A$. 2021, vol. 804, 140515.

[12] LIN, L., LIU, Z., BAI, S., ZHOU, Y., LIU, W., LV, Q. Effects of Ge and Ag additions on quench sensitivity and mechanical properties of an Al-Zn-Mg-Cu alloy. Materials Science and Engineering: A. 2017, vol. 682, pp. 640647. 